\title{
Maré sitiada: o discurso midiático sobre a ocupação militar do Complexo da Maré1
}

\author{
Renata da Silva Souza²
} Comunicação e Cultura da Escola de Comunicação da Universidade Federal do Rio de Janeiro (ECO/UFRJ). renatasouza.ufrj@gmail.com 


\section{Resumo}

A Maré, conjunto de favelas localizado na zona norte do Rio de Janeiro, foi ocupada em abril de 2014 por forças militares de pacificação, engenhosa operação que envolveu um total de 2.700 militares com 20 tanques blindados. Assim, este artigo toma como objeto a cobertura midiática da ocupação militar, utilizando como método a análise das reportagens publicadas em tempo real durante a invasão. A ideia é esboçar as tensões entre o discurso dos meios de comunicação e as estratégias informativas engendradas nas redes sociais por narradores comunitários da Maré. Tais iniciativas podem colocar em disputa novas versões dos fatos. Serão traçadas abordagens teóricas que deem conta da análise a respeito da ordem do discurso, a partir de Foucault e de uma breve reflexão sobre o discurso do sofrimento.

\section{Palavras-chave}

Maré, favela, discurso, midiático, militarização.

\section{Abstract}

The Complexo da Maré, a group of 16 slums in northern Rio de Janeiro, was occupied in April 2014 by Federal troops, an ingenious operation that involved a total of 2,700 military personnel on 20 armored tanks. Thus, this article presents the dimension of media coverage of this military occupation, using as method the analysis of headlines published in real time during the invasion. The idea is to describe the tensions between the official discourse of public power, absorbed by mainstream media, and informational strategies produced through social networks by community narrators. These initiatives may present new versions of the events. Theoretical approaches will be drawn to analyze the order of discourse, based on Foucault and a brief reflection on the discourse of suffering.

\section{Keywords}

Maré, slums, discourse, media, military. 


\section{A ordem do discurso}

A fabricação do discurso, de acordo com Michel Foucault (2012), obedece a uma série de procedimentos. Com o objetivo de limitar seus poderes e perigos, essa produção é controlada, selecionada, organizada e redistribuída. Desse modo, em nossa sociedade, há mecanismos de exclusão que se revelam na interdição do direito de dizer tudo. É descabido falar sobre tudo, no entanto, é facultado o direito de fala a alguns privilegiados, os sujeitos de fala. Nesse sentido, nas áreas relativas à sexualidade e à política, o discurso se caracteriza por sua obscuridade e sua relação com as interdições ligadas ao desejo e ao poder. É onde se processa o poder ilimitado sobre o corpo social.

Foucault identifica três sistemas de exclusão, que se valem da separação e rejeição, concedendo capilaridade e organizando o discurso: a palavra proibida, que se caracteriza pela fala do louco expondo a oposição entre razão e loucura; a segregação da loucura; e a vontade de verdade, capitaneada pela dicotomia entre verdadeiro e falso. O autor rememora que os poetas gregos, no século VI, se valiam do discurso verdadeiro para pronunciar o futuro. Tal atividade provocava a adesão da população a um espetáculo completamente ritualizado. No século VII, no entanto, o sofista perde seu reinado, já que o discurso de verdade se afastou do ato ritualizado de enunciação e se estabeleceu no próprio enunciado. Ao se estabelecer uma separação entre Hesíodo e Platão, houve consequentemente a dicotomia entre discurso verdadeiro e discurso falso. 0 discurso verdadeiro deixou de ser desejável, porque se distanciou do discurso ligado ao poder.

O discurso ganha outros contornos na dimensão do acontecimento e do acaso, classificada por Foucault como procedimento interno de controle e delimitação do discurso. São elas o comentário e o autor. O comentário articula o acaso do discurso, uma vez que relaciona o texto primeiro ao texto segundo e permite construir novos discursos, uma possibilidade aberta de fala. Já o autor, corresponde, mais que ao indivíduo falante ou escritor, ao princípio de unidade do discurso e sua coerência. "O comentário limitava o acaso do discurso pelo 
jogo de uma identidade que teria a forma da repetição e do mesmo. O princípio do autor limita esse mesmo acaso pelo jogo de uma identidade que tem a forma da individualidade do eu" (FOUCAULT, 2012, p. 28).

Outro princípio de limitação do discurso é a disciplina, que se opõe aos princípios do comentário e do autor. A disciplina, diferente do princípio do autor, se caracteriza pelo domínio da técnica e de métodos. Em oposição ao comentário, a disciplina não pressupõe um ponto de partida, já que prenuncia a construção de novos enunciados e formulações indefinidamente. A disciplina fixa os limites do discurso através do jogo de uma identidade que precisa ser constantemente reatualizada, obedecendo às regras impostas pela própria disciplina. Há ainda outro grupo de procedimento que, ao determinar as condições de funcionamento de controle do discurso, promove a "rarefação dos sujeitos que falam". Para se ter acesso à ordem do discurso, é necessário dominar determinadas regras e atender a certas exigências.

As doutrinas, sejam elas religiosas, políticas ou filosóficas, se qualificam como o inverso de uma "sociedade de discurso", uma vez que tende a difundirse. No entanto, realiza uma dupla sujeição, relativa tanto ao sujeito que fala o discurso como aos discursos do grupo. Em uma escala mais ampla, há a apropriação social do discurso realizada, por exemplo, pelo sistema de educação, ferramenta política capaz de manter ou modificar a apropriação do discurso, uma vez que detém saberes e poderes específicos.

Para Foucault (2012), o discurso filosófico "nada mais é do que a reverberação de uma verdade nascendo diante de seus próprios olhos; e quando tudo pode, enfim, tomar a forma do discurso [...] isso se dá porque todas as coisas podem voltar à interioridade silenciosa da consciência de si" (p. 46). Sendo assim, "os discursos devem ser tratados como práticas descontínuas, que se cruzam por vezes, mas também se ignoram ou se excluem" (Ibid., p. 50). "O discurso não é simplesmente aquilo que traduz as lutas ou os sistemas de dominação, mas aquilo por que, pelo que se luta, o poder do qual nos queremos apoderar" (Ibid., p. 10). 
Desse modo, não há surpresa sobre a dominação de um discurso midiático que se revela como hegemônico na manutenção do poder daqueles que detêm o direito de fala. Ou seja, as elites formulam seus discursos para sustentar seus privilégios e disseminar em seus meios de comunicação o discurso hegemônico que identifica os despossuídos financeiramente como inimigos, como classe perigosa que deve ser controlada e vigiada.

\section{O discurso midiático sobre a favela}

O discurso hegemônico sobre a favela, angariado pelo discurso midiático, a descreve como um espaço dominado pelo tráfico de drogas, pela violência e falta de condições humanas de sobrevivência. Em uma pesquisa realizada pelo Centro de Estudos de Segurança e Cidadania da Universidade Candido Mendes (CESeC), em 2004, que resultou na publicação do livro Mídia e Violência: tendências na cobertura de criminalidade e segurança no Brasil (RAMOS; PAIVA, 2007), um dos consensos encontrados entre os jornalistas é o reconhecimento de que os veículos em que trabalham são os responsáveis pela caracterização das favelas como espaços privativos da violência. Isso porque a pauta prioritária dá conta das operações policiais, dos tiroteios, execuções, etc. Alguns alegam falta de "fontes legítimas", ou mesmo uma recepção negativa por parte da população, ao que a pesquisa indagou corretamente: "Será que os repórteres estão limitando a sua presença nas favelas ao acompanhamento de ações policiais por causa da hostilidade da população, ou passaram a encontrar uma recepção hostil por só acompanharem as ações policiais?" (Ibid., p. 77).

A pesquisa relaciona a abordagem monotemática à elitização das redações, desde a década de 1970, quando o diploma universitário passou a ser obrigatório para o exercício da profissão. Isso caracterizaria o aumento do apuro técnico em detrimento de uma aproximação mais orgânica do repórter ao cotidiano dos moradores de favela, algo já experimentado pelos "jornalistas da antiga". Outra hipótese seria o reduzido número de pessoas negras e/ou ligadas às comunidades dentro das redações. No entanto, conclui-se que não se deve 
creditar a cobertura estigmatizante sobre a favela apenas ao repórter. As pautas seguem uma linha editorial previamente defina pelo veículo de comunicação que prioriza a cobertura dos bairros nobres, onde seus leitores "não gostam muito de favela", como afirmou uma das jornalistas entrevistadas. Aliada a tudo isso está a suposta sensação de insegurança gerada nos repórteres após a execução do jornalista da TV Globo, Tim Lopes, no Complexo do Alemão.

Uma das jornalistas entrevistadas pela pesquisa, Roberta Pennafort, alertou para a falta de sensibilidade de seus colegas ao cobrirem o sofrimento dos moradores de favela. Ela narrou que em uma cobertura sobre um deslizamento de terra em um morro, que havia vitimado três crianças, uma repórter fazia perguntas completamente alheias à dor da família. Pennafort garante que os repórteres, em geral, na apuração in loco de tragédias dramáticas com famílias da classe média ou alta costumam ser mais respeitosos e chegam a compartilhar da dor do outro.

Tal relato reforça a percepção empírica de que os discursos de sofrimento na construção midiática não se qualificam pela neutralidade social. Quando a vítima que sofre, por exemplo, é um morador de favela que fora atingido por um tiro de "bala perdida" durante conflito entre policiais e traficantes, a vítima já é vista com desconfiança. Ainda mais se corporificar características do perfil de um suposto criminoso, ou seja, jovem, pobre e negro. Ocorre ambiguidade sobre a vítima, que muitas vezes precisa provar sua inocência. Quando a vítima é atingida de forma fatal, sua família encabeça uma luta inglória para provar sua inocência post mortem, isso ocorre porque dificilmente os meios de comunicação tradicionais articulam o direito ao contraditório em suas coberturas jornalísticas. A palavra final é dada pela "fonte oficial", a própria polícia, como se observa na manchete: "Delegado diz que DG estava ao lado de traficantes durante o confronto com a polícia" (DELEGADO..., 2014), sobre a morte do dançarino do programa Esquenta, Douglas Rafael da Silva, no morro Pavão-Pavãozinho. É como se o fato de ele estar na favela ao lado de um suposto traficante o levasse à justificada morte. Se o fato ocorresse a 100 metros do morro, em Copacabana, 
e a vítima fosse um jovem branco de classe média, haveria uma comoção geral sem levantar suspeitas sobre a índole da vítima.

A criminalização da vítima faz parte de uma estratégia de construção de supostos inimigos violentos, e determina quais seriam as vítimas inocentes. Paulo Vaz qualificou os moradores de favela, por sua conexão espacial e midiática com os traficantes, como "criminosos virtuais". Menospreza-se sua dor e sofrimento: "Se duvidarmos mais da versão da polícia do que de sua inocência, ainda assim poderemos pacificar nossa indignação pensando que toda 'guerra' implica sacrifícios" (VAZ; POMBO; SÁ-CARVALHO, 2005, p. 20). Cabe ressaltar, no entanto, que sendo a vítima culpada ou inocente, o código de ética do jornalista prevê a defesa intransigente dos direitos humanos. No entanto, tais discursos revelam a distinção entre a vida que vale mais e a que vale menos; entre o extermínio justificado e aceito e a morte inaceitável e injustificada.

O jornalista, no papel de observador nato, ignora o sofrimento real, já que não há uma empatia ou identificação com a vítima da favela. Uma vez que esta não é reconhecida como igual, a diferença econômica e de cor lhe causam indiferença. É o preconceito moral que o impede de reconhecer o sofrimento. Muitas vezes, revelam-se inquisidores diante de crimes que interrompem uma suposta calmaria dos indivíduos comuns e da ineficácia de ação do Estado, uma vez que uma espécie de sofrimento torna-se contingente. A consequente busca por bodes expiatórios se dá como "crítica moral da política e legitima a vingança como modo de lidar com todos aqueles que a moralidade constrói como monstros" (VAZ, 2010, p. 163).

O surgimento de tabloides a baixo custo destinados às classes C, D e E também não diminuiu o universo de abordagens estereotipadas sobre as comunidades, pelo contrário, aumentou o sensacionalismo sobre a cobertura policial. Desse modo, além de notícias esporádicas sobre os espetáculos artísticos promovidos por organizações não-governamentais, o que vira notícia sobre a favela é aquilo que pode ser qualificado como exótico, como a manchete "Único padre exorcista do Rio é da Maré", publicado no jornal O Dia (SALOMÃO; FREIRE, 2014). 


\section{Maré militarizada e midiatizada}

A cobertura midiática sobre a ocupação militar da Maré, um conjunto de 16 favelas localizadas na zona norte do Rio de Janeiro, ocorrida no final de março de 2014, expõe concretamente o investimento em abordagem policialesca sobre as comunidades antes e durante o fato ocorrido. Com a manchete "Complexo da Maré terá um militar para cada 55 moradores" (NASCIMENTO et al., 2014). A reportagem antecipa com detalhes a operação e forja uma expectativa que gera sofrimento anterior à própria ação do Estado. Assim, segue o texto que a qualifica, já em sua primeira linha, como "O pedido de socorro do estado ao governo federal para enfrentar os criminosos responsáveis pelos ataques em série a bases de UPPs" (Ibid.). O lide é desmentido no próprio corpo do texto, em que o então secretário de segurança afirma que tal inciativa não teria relação com os ataques que ocorreram às UPPs em diferentes favelas da cidade. No entanto, o texto continua articulado nessa mesma hipótese. A matéria segue com uma imagem aérea panorâmica em que a Maré aparece margeando as linhas vermelha e amarela, além da Avenida Brasil. A reportagem também oferece um infográfico em que o leitor pode analisar o mapa do conjunto de favelas.

Os mapas e infográficos não são expostos aleatoriamente para ilustrar a reportagem, não são reflexos de uma espacialidade exterior, como revela De Certeau (2008). Representam atos de fala que organizam o território com seus possíveis rumos. Sendo assim, o mapa "faz ver" os locais e delimita as trajetórias permitidas, em contraposição àquelas que são proibidas. Portanto, não é difícil concluir que o mapa "faz ver" a favela para o interlocutor que não a conhece e demonstra o caminho que não se deve seguir, já que ali o perigo é iminente. Ao mesmo tempo, tais notícias midiáticas justificam qualquer ato inconstitucional em um território favelado. Vide a manchete "Justiça expede mandado coletivo e polícia pode fazer buscas em todas as casas do Parque União e da Nova Holanda" (SOARES, 2014). A reportagem se limitou à notícia em si, e não se propôs a problematizar a aberração "legal" de um mandado coletivo. Já está previamente legitimado o poder da própria Justiça e das forças policiais em violar "legalmente" 
as casas dos favelados. É sabido que a Constituição Brasileira, em seu Art. $5^{0}$ XI - determina que "a casa é asilo inviolável do indivíduo, ninguém nela podendo penetrar sem consentimento do morador, salvo em caso de flagrante delito ou desastre" (BRASIL, 2014).

"Ocupação no Complexo da Maré é concluída em apenas 15 minutos" (OCUPAÇÃO..., 2014). A imagem selecionada para ilustrar a reportagem estampa agentes das forças policiais fortemente armados ao lado de uma senhora que passeia com o seu cão e uma sacola na mão. O texto segue com a descrição do funcionamento normal do comércio e o elogio de uma moradora, que não quis se identificar, dizendo que estava adorando a ação. A cobertura televisiva foi feita ao vivo pela principal emissora do Rio de Janeiro, a Rede Globo. A programação teve sua grade alterada e, ao invés de exibir o programa Globo Rural, foi transmitida a ocupação da Maré. As imagens exibidas deram conta da movimentação ostensiva das tropas de mais de 2 mil homens, com seus tanques de guerra terrestres e helicópteros blindados. Enquanto as forças de segurança ocupavam o local, jornalistas as seguiam com suas câmeras audiovisuais e equipamentos fotográficos. A interpretação quase que imediata das imagens, sem o áudio, revela uma tropa de homens exageradamente armados que dão cobertura à invasão dos profissionais de mídia a uma favela. Além dessas cenas de ação, as câmeras se voltam para o tradicional ritual do Estado de ocupação de um território considerado hostil. Em uma praça pública, policiais da cavalaria trotam em seus animais e ensaiam uma aproximação amistosa da população. Crianças, jovens e idosos são convidados a montarem os cavalos da tropa, em um clima pacífico. Logo depois, o ritual se encerra com a cerimônia de hasteamento das bandeiras do Brasil e do estado do Rio de Janeiro. O grand finale fica por conta da soltura de pombas brancas no território teoricamente pacificado pelas forças de segurança. Uma cobertura coerente à tentativa de pacificação das tensões sociais.

Em paralelo a essa abordagem midiática, moradores usaram as redes sociais para comentar a ocupação. Com a criação de uma comunidade virtual no 
Facebook denominada Maré Vive e a utilização de hashtags como "\#MaréVive", "\#OquetemnaMaré" e "\#DedentrodaMaré", os moradores protagonizam o papel de narradores das mazelas do Estado de dentro do front. A rede social escancarou o espaço de disputa de versões e discursos sobre esse episódio na Maré. Um dos comentários de moradores dizia: "Mandados coletivos de busca? Traduzindo, todos que moram na favela são previamente suspeitos de serem criminosos. Vai ver se tem mandado coletivo nos condomínios de luxo, onde o tráfico corre solto?". A proximidade entre a data da ação na Maré e o dia em que se remomora os 50 anos da Ditadura Militar gerou inúmeras conexões. Parte dos moradores qualificou a ocupação militar como estado de sítio e de exceção em plena democracia.

A comunidade virtual Maré Vive divulgou inúmeros casos de abusos de autoridade que não foram veiculados nas mídias tradicionais. Segue um dos relatos: "Senti uma respiração forte e ofegante com um hálito quente em meu rosto. Meio sonolenta, abro os olhos e me deparo com um cão e homens de preto a minha volta. Susto, medo e revolta. Meu quarto tomado por desconhecidos da lei e perguntas que não sei responder. Todos os dias eles vêm na minha casa. Já não durmo de camisola, porque essa visita pela manhã virou rotina e tenho que estar preparada para recebê-los. Hoje já entraram duas vezes. Minha casa virou o Batalhão da Polícia Militar".

No mundo real, um profissional da mídia mais atento e preocupado com as mazelas sociais não deixaria uma comunidade virtual como essa passar despercebida. São quase 10 mil seguidores, entre moradores e curiosos, que fazem relatos diários sobre a situação na Maré. Ou seja, ignora-se uma fonte legítima. Isso porque tais moradores se autodeclaram envolvidos com a luta pelos direitos humanos fundamentais dos cidadãos que vivem em favelas e estão dispostos a denunciar casos de abusos ocorridos com familiares e vizinhos. Contudo, a escolha midiática de cobrir a ocupação privilegiando as fontes ditas oficiais não passa despercebida pela própria comunidade. Em uma nota pública, veicula no dia $1^{0}$ de abril de 2014, a comunidade questiona a 
promoção de notícias que qualificam a "invasão militar" como o maior sucesso dos últimos tempos. Segundo eles, contrariamente ao espetáculo midiático, são recorrentes os relatos sobre violações e abusos. "Policiais entrando nas casas sem mandado; com 'toca ninja' e ameaçando moradores de morte; depredando bens e roubando eletrodomésticos sem nota fiscal; tratando moradores com violência verbal e apontando armas e fuzis para os seus rostos; constrangendo e agredindo crianças" (MARÉ VIVE, 2014).

Em outra nota, publicada em 11 de abril, a comunidade afirma que um Estado que utiliza tanques de guerra contra a população não busca o diálogo e não se preocupa com a manutenção de direitos. Uma das principais estratégias da página é a utilização de um discurso irônico sobre a cobertura midiática, como se verifica na Figura 1.

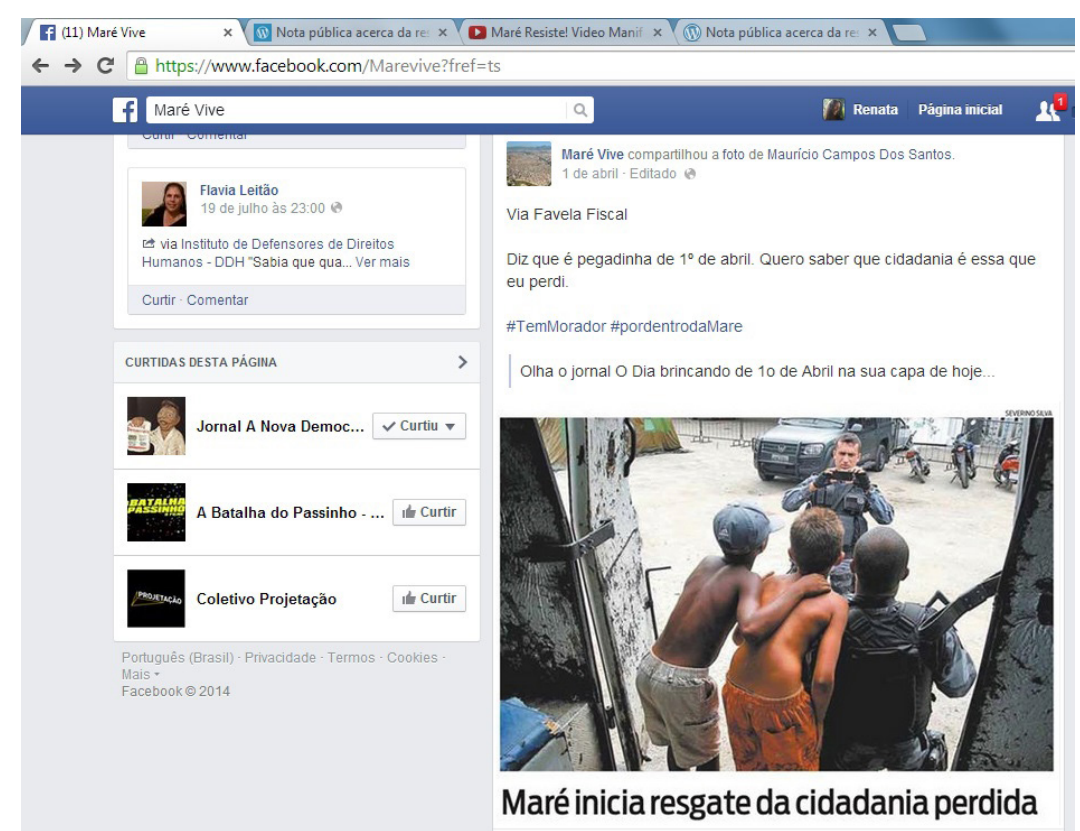

Figura 1: A comunidade de Facebook Maré Vive compartilha comentário da página "Favela Fiscal", que ironiza a manchete do jornal O Dia sobre o resgate da cidadania perdida da Maré.

Em outro post, a comunidade critica a tentativa da linha editorial do jornal O Globo de criminalizar os moradores que protestam contra as arbitrariedades cometidas pelas forças de pacificação, como revela a Figura 2. 


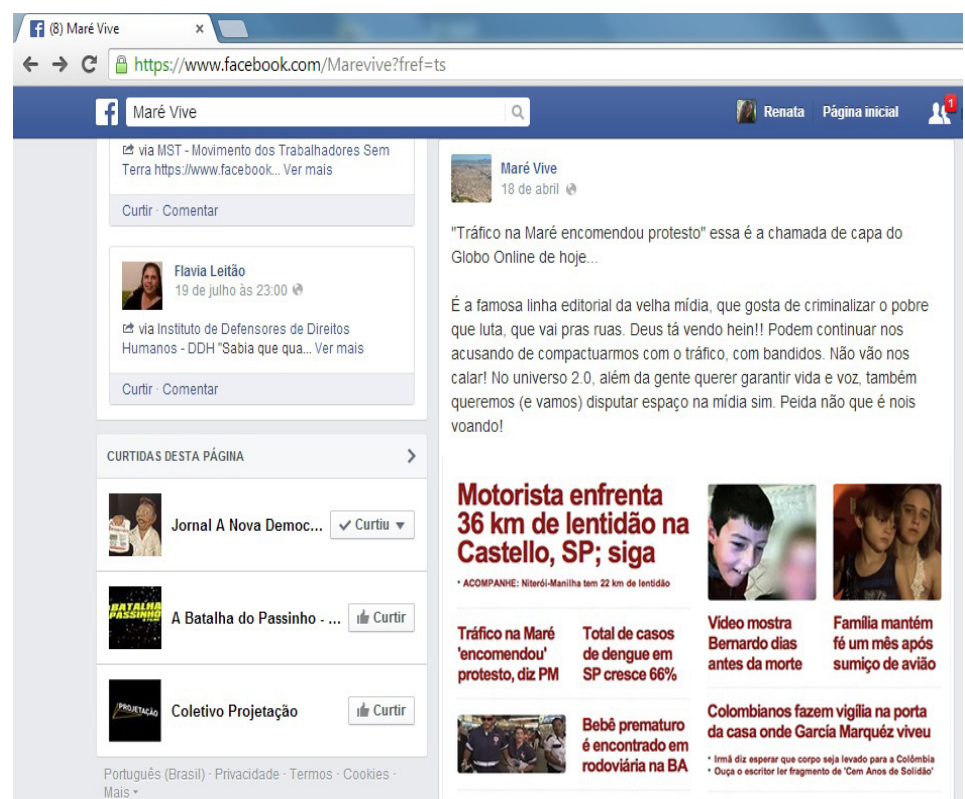

Figura 2: A comunidade Maré Vive questiona a linha editorial do jornal $O$ Globo que, a partir de sua manchete, criminaliza os protestos protagonizados por moradores contra a militarização da favela

\section{Considerando que a Maré Vive}

Entre as propostas de solução apontadas pela pesquisa do Cesec para uma cobertura mais plural sobre as favelas está a criação de novos canais de diálogo com a população das comunidades. Uma das formas de acesso mais interessante seria a interlocução com organizações não governamentais e entidades de direitos humanos. No entanto, é inadequada e descabida a sugestão de "promover encontros sistemáticos com suas lideranças, a exemplo do que vem fazendo até instituições mais fechadas, como a Polícia Militar" (RAMOS; PAIVA, 2007, p. 86). Mesmo reconhecendo que o livro foi editado antes da política de pacificação das favelas, não é aconselhável a reprodução de qualquer estratégia já pensada e executada pela Polícia Militar para se ter acesso à comunidade. Esses encontros com as forças militares são geridos de maneira autoritária e intensificam a relação conflituosa, de desconfiança e insegurança com relação aos órgãos de Segurança Pública e da própria imprensa. 
Além disso, a análise do discurso midiático sobre a ocupação militar da Maré não deixa dúvidas sobre a tentativa de pacificação das relações sociais. A principal característica dessa iniciativa se revela na abordagem jornalística em que se expressa, no primeiro momento, uma ideia de que tal processo se deu com sucesso e aceitação popular. Logo, as notícias que se seguem relatam a morte de um adolescente horas após à ocupação, nas proximidades do local onde fora hasteada a bandeira do Brasil. As reportagens revelam apenas a versão das forças policiais de que o menino teria sido vítima de uma guerra entre facções. Não se questionou em nenhum momento como um adolescente foi assassinado em plena luz do dia no mesmo instante em que a favela acabara de ser ocupada por mais de 2 mil homens da Segurança Pública. Isso demonstra que, além de sugerir uma falsa pacificação dos conflitos ali existentes, o discurso midiático forja a naturalização da perda de vidas em um processo dito de pacificação cujo efeito colateral, a morte do jovem, já está antecipadamente justificado.

Sendo assim, a construção de possibilidades de novas versões sobre os fatos não pode ser negligenciada. Uma iniciativa como a comunidade virtual Maré Viva é capaz de pôr em xeque os discursos cristalizados que direcionam às favelas todo tipo de estereótipos e preconceitos. Tal disputa é sem dúvida inglória, uma vez que a opinião pública não é tão penetrável como se imagina. Mas, como bem expressou a Maré Vive, na Figura 2, o universo 2.0 é um espaço que cabe probabilidades infinitas que ainda não foram exploradas e experimentadas ao seu máximo. É nesses espaços, seja na internet ou em meios físicos como as rádios, jornais e TVs comunitárias, que a favela reivindica e realiza o seu direito de fala. 


\section{Referências}

BRASIL. Constituição (1988). Título II - Dos direitos e garantias fundamentais. Capítulo I - Dos direitos e deveres individuais e coletivos. Art. 50 - XI. Disponível em: <http://www.observatoriodainfancia.com.br/IMG/pdf/doc-47.pdf>. Acesso em: 30 abr. 2014.

CAMPOS, A. Do Quilombo à Favela: a produção do "Espaço Criminalizado" no Rio de Janeiro. Rio de Janeiro: Bertrand Brasil, 2011.

CENSO MARÉ 2000. Quem somos, quantos somos, o que fazemos? Rio de Janeiro: Ceasm, 2000.

COSTA, B. Ocupação no Complexo da Maré é concluída em apenas 15 minutos. Extra, 30 mar. 2013. Disponível em: <http://extra.globo.com/casos-de-policia/ ocupacao-no-complexo-da-mare-concluida-em-apenas-15-minutos-12033951. html>. Acesso em: 15 jul. 2014.

DAVIS, M. Planeta Favela. São Paulo: Boitempo, 2006.

DE CERTEAU, M. A invenção do cotidiano: Artes de fazer. Petrópolis: Vozes, 2008.

DELEGADO diz que DG estava ao lado de traficantes durante confronto com a polícia. R7 2014. Disponível em: <http://noticias.r7.com/fala-brasil/videos/ delegado-diz-que-dg-estava-ao-lado-de-traficantes-durante-confronto-com-apolicia-17102015>. Acesso em: 21 out. 2015.

FOUCAULT, M. A ordem do discurso: aula inaugural no Collège de France, pronunciada em 2 de dezembro de 1970. Tradução de Laura Fraga de Almeida Sampaio. 22. ed. São Paulo: Edições Loyola, 2012. 
INSTITUTO BRASILEIRO DE GEOGRAFIA E ESTATÍSTICA. Censo demográfico de 2010. Brasil, 2010.

MARÉ VIVE. Manifesto e Nota pública acerca da resistência popular contra a ditadura militar na Maré. Maré Vive, 2014. Disponível em: <http://marevive. wordpress.com/>. Acesso em: 20 jul. 2014.

NASCIMENTO, C. et al. Complexo da Maré terá um militar para cada 55 moradores. O Dia - 25/3/14). Disponível em http://odia.ig.com.br/noticia/ rio-de-janeiro/2014-03-25/complexo-da-mare-tera-um-militar-para-cada-55moradores.html. Acesso em: 15 jun. 2014.

OCUPAÇÃO no Complexo da Maré é concluída em apenas 15 minutos. Extra, 30 mar. 2014. Disponível em: <http://extra.globo.com/casos-de-policia/ocupacaono-complexo-da-mare-concluida-em-apenas-15-minutos-12033951.html>. Acesso em: 21 out. 2015.

PAIVA, R. O Espírito Comum - Comunidade, Mídia e Globalismo. Rio de Janeiro: Mauad, 2003.

Comunicação e Cultura das Minorias. São Paulo: Paulus, 2005.

. (Org.). O retorno da comunidade. Rio de Janeiro: Mauad X, 2007.

RAMOS, S.; PAIVA, A. Mídia e Violência: tendências na cobertura de criminalidade e segurança no Brasil. Rio de Janeiro: IUPERJ, 2007.

SALOMÃO; FREIRE, 2014. Único padre exorcista do Rio é da Maré. O Dia. Disponível em: <http://odia.ig.com.br/noticia/rio-de-janeiro/2014-04-07/ unico-padre-exorcista-do-rio-e-da-mare.html>. Acesso em 21 out. 2015. 
SOARES, R. Justiça expede mandado coletivo e polícia pode fazer buscas em todas as casas do Parque União e da Nova Holanda. Extra, 29 mar. 2014. Disponível em: <http://extra.globo.com/casos-de-policia/justica-expedemandado-coletivo-policia-pode-fazer-buscas-em-todas-as-casas-do-parqueuniao-da-nova-holanda-12026896.html>. Acesso em: 15 jun. 2014.

VAZ, P.; POMBO, M.; SÁ-CARVALHO, C. Risco e sofrimento evitável: a imagem da polícia no noticiário de crime. In: E-Compós, v. 3, n. 22, dez. 2005. [periódico na Internet]. Disponível em: <http://compos.org.br/seer/index.php/e-compos/ article/viewFile/46/46>. Acesso em: 10 jun. 2014.

VAZ, P. A vida feliz da vítima. In: FILHO, J. F. (Org.). Ser feliz hoje. Rio de Janeiro: FGV, 2010.

submetido em: 26 mai. 2015 | aprovado em: 07 ago. 2015 